\title{
Projecting flood hazard under climate change: an alternative approach to model chains
}

\author{
J. M. Delgado ${ }^{1}$, B. Merz ${ }^{2}$, and H. Apel ${ }^{2}$ \\ ${ }^{1}$ University of Potsdam, Institute of Earth and Environmental Science, Karl-Liebknecht-Str. 24-25, \\ 14476 Potsdam-Golm, Germany \\ ${ }^{2}$ GFZ German Research Centre for Geosciences, Section 5.4, Hydrology, Telegrafenberg, 14473 Potsdam, Germany
}

Correspondence to: J. M. Delgado (martinsd@uni-potsdam.de)

Received: 30 October 2013 - Published in Nat. Hazards Earth Syst. Sci. Discuss.: 10 December 2013

Revised: - - Accepted: 12 May 2014 - Published: 23 June 2014

\begin{abstract}
Flood hazard projections under climate change are typically derived by applying model chains consisting of the following elements: "emission scenario - global climate model - downscaling, possibly including bias correction hydrological model - flood frequency analysis". To date, this approach yields very uncertain results, due to the difficulties of global and regional climate models to represent precipitation. The implementation of such model chains requires major efforts, and their complexity is high.

We propose for the Mekong River an alternative approach which is based on a shortened model chain: "emission scenario - global climate model - non-stationary flood frequency model". The underlying idea is to use a link between the Western Pacific monsoon and local flood characteristics: the variance of the monsoon drives a non-stationary flood frequency model, yielding a direct estimate of flood probabilities. This approach bypasses the uncertain precipitation, since the monsoon variance is derived from large-scale wind fields which are better represented by climate models. The simplicity of the monsoon-flood link allows deriving large ensembles of flood projections under climate change. We conclude that this is a worthwhile, complementary approach to the typical model chains in catchments where a substantial link between climate and floods is found.
\end{abstract}

\section{Introduction}

The frequency of extreme hydrologic events is expected to increase due to climate change (Milly et al., 2005; Knox, 2000; Allen and Ingram, 2002). There are unfortunately large uncertainties when it comes to modelling precipitation, in particular in tropical and monsoon regions such as Southeast Asia (Wang et al., 2004; Randall et al., 2007; Lambert and Boer, 2001; Turner and Annamalai, 2012). This handicap of climate models presents a serious challenge for projecting changes in flood frequency and intensity.

There is low confidence in projections of changes in fluvial floods (Milly et al., 2002; Jain and Lall, 2001; Delgado et al., 2012a). Thus, shifts and trends in the variance of atmospheric circulation patterns are especially important, since they significantly contribute to changes in the probability of extreme events, as changes in variability alter the tails of the extreme value distributions applied to estimate the probability of the extreme events. Changes in variance have been witnessed in the past, both for atmospheric circulation and flood discharges (Delgado et al., 2012a; Whitcher et al., 2002; Villarini et al., 2009), while projections of future streamflow and precipitation estimate significant changes on variance which can have impacts on flood frequency (Sperna Weiland et al., 2011; Arnell, 2003).

Flood design, flood risk management and projections of flood hazard under climate change can profit from linkages between atmospheric circulation and streamflow. The methodology usually adopted for estimating the sensitivity of streamflow to atmospheric circulation is to set up a model chain. Climate change studies typically adopt the following chain: "emission scenario - global climate model - downscaling, possibly including bias correction - hydrological model - flood frequency analysis". This approach is associated with a number of problems; some of the more important ones are (1) the complexity of such model chains is 


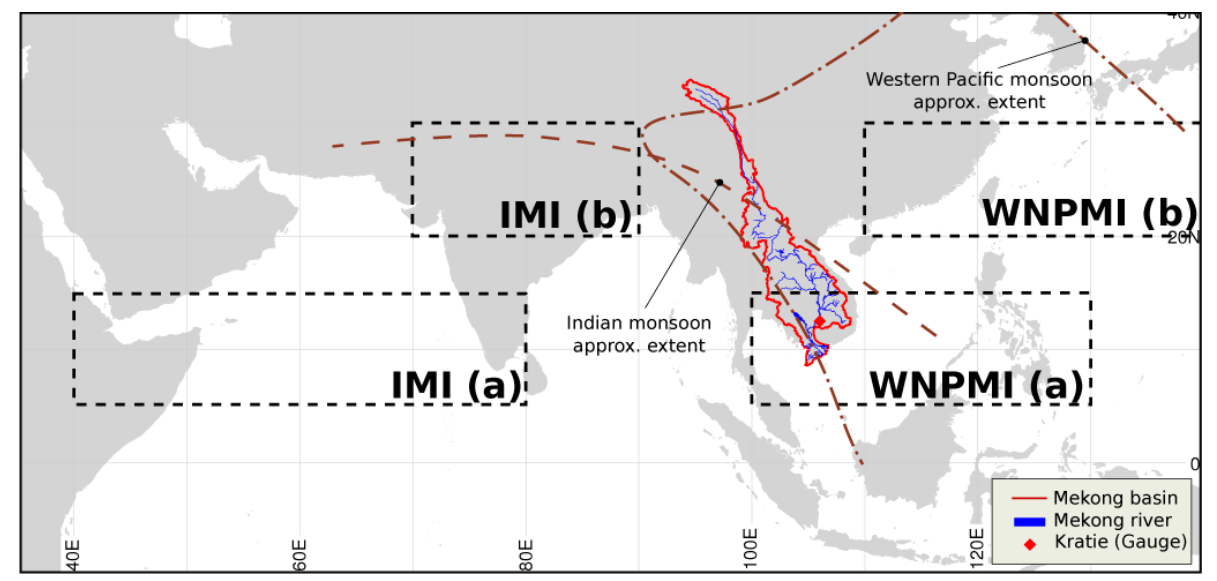

Figure 1. South and Southeast Asia. The Mekong River is depicted, together with the gauge used as data source in this study. The Mekong River is located in the transition zone between the Indian and the Western Pacific monsoon regimes (maximum monsoon extents adapted from Holmes et al., 2009). The boxes for averaging both IMI and WNPMI are shown.

enormous, impeding the understanding of how changes in the climate system propagate to changes in flood frequency (Blöschl and Montanari, 2009). (2) The implementation and computation of climate change scenarios require a huge effort, in particular when ensembles of model chains are established. (3) Uncertainty analyses show that, to date, the results of these model chains are associated with high uncertainty. Typically, the variability between different model chains is higher than the change signal (Teutschbein and Seibert, 2010; Lauri et al., 2012; Kingston et al., 2011). This is, among others, a consequence of the low skill of global and regional climate models in simulating extreme precipitation, particularly in tropical monsoon regions (Douville et al., 2005; Wang et al., 2004; Deser et al., 2010; Turner and Annamalai, 2012).

If a sufficiently strong link between climate state and flood generation exists, flood frequency can be predicted based on atmospheric circulation patterns. For example, ENSO (El Niño-Southern Oscillation) has been linked to floods all around the world (Ward et al., 2014), such as in Peru (Waylen and Caviedes, 1986), in the United States (Cayan et al., 1999; Jain and Lall, 2000, 2001; Sankarasubramanian and Lall, 2003) and China (Zhang et al., 2007). Other climate modes, such as the Pacific Decadal Oscillation, the North Atlantic Oscillation or selected weather patterns have been shown to influence the flood regime and to lead to flood episodes of varying intensity as well (Cayan, 1996; Jain and Lall, 2000; Pizarro and Upmanu Lall, 2002; Bouwer et al., 2006; Kingston et al., 2006).

We apply this idea of linking floods (Fig. 1) to climate (Tramblay et al., 2013; López and Francés, 2013), in order to derive flood projections under climate change. Large-scale monsoon intensity is used to explain the scale parameter of the non-stationary flood frequency distribution representing the variability of floods in the lower Mekong Basin. By link- ing flood hazards directly with monsoon intensity, we significantly shorten the climate change model chain to "emission scenario - global climate model - non-stationary flood frequency model". This approach is not only much simpler, but it avoids relying on precipitation for flood projections. Precipitation is poorly simulated by global and regional climate models in this region, as the monsoon dynamics are still both poorly understood and represented in general circulation models (Turner and Annamalai, 2012; Wang et al., 2004). Instead, large-scale wind fields from GCMs are directly used for the estimation of flood frequencies, as the monsoon intensity is described by monsoon indexes calculated from the strength of those wind fields in defined areas.

Previous work by Delgado et al. (2012a) showed that the variance of the Western North Pacific (WNP) monsoon index and of the annual maximum discharge in the lower Mekong River followed the same pattern: from the mid-20th century to 1976 they remained low, only to later experience a phase of enhancement, and increase the flood frequency. It has also been shown that the link between the WNP monsoon and summer precipitation is comparably stronger than for the Indian monsoon in most of the lower Mekong Basin. Different climate regimes have been shown to occur in the Pacific (Mantua et al., 1997), due to its decadal oscillation. We propose a representation of these different climate regimes and capture its impact on flood hazard.

The innovation in the methodology is twofold. First, we directly apply the link between flood probability and a climate index in flood projections under climate change. Further, we focus on changes in variance, namely in variance of the atmospheric circulation as a defining driver of change, and in variance of flood peaks as a more important factor compared to the mean flood behaviour. 


\section{Methods and data}

In this paper three different flood frequency models were used. The simplest was a stationary log-normal distribution that was fitted to the measured annual maximum discharge. A second model was a non-stationary log-normal distribution, which was fitted to the measured annual maximum discharge, but whose scale parameter was regressed on the variance of the WNP monsoon index (calculated with reanalysis data). The third model was based on the previous nonstationary log-normal distribution. Its parameters were kept, except for the scale parameter, which was regressed on the variance of the WNP monsoon index from the GCMs. This last model was used for making projections of flood frequency under climate change.

\subsection{Data}

The discharge data used in this study is the annual maximum discharge for the Mekong River station of Kratie. This station is very significant for the flood levels in the Mekong Delta, constituting a natural boundary condition for the Delta (Fig. 1). Since the river cross section in Kratie is not well defined due to common overbank flow and difficulties in obtaining the rating curves for some years, the results of this work were also validated against data from the upstream station of Stung Treng. The data were quality checked by the data provider (MRC 2005).

The climatic data necessary for this study was the zonal component of the $850 \mathrm{hPa}$ wind velocity. The annual monsoon intensity is composed of the average wind velocity over a defined region minus the average wind velocity over another region during June, July, August and September. The regions are a rectangular area between Southern Indochina and Southern Philippines and another area including Southern China and the East China Sea (Fig. 1). The difference between the wind velocity within these areas is a good indicator of the intensity of the monsoon (Wang et al., 2001) (in Fig. 1, the monsoon indexes correspond to the averages over $a$ minus the averages over $b$ ). The monsoon index for the 20th century was obtained from Kajikawa and Wang (2012).

The climate change (CC) and 20th century baseline scenario (20C) experiments used were obtained from the CERA database (http://www.mad.zmaw.de/). Each experiment is made of one coupled GCM, which is a combination of land surface parameterisation, ocean circulation and atmospheric circulation, and a set of $\mathrm{CC}$ emission scenarios, for which one or more runs are performed by each institution. Table 1 lists the institutions, the number of runs for each scenario and the respective reference. Although they were run by different institutions and with different land surface, ice cover and ocean circulation models, most of these coupled GCMs are based on the ECHAM, ARPEGE and Hadley Centre atmospheric circulation models. Figure 2 shows which atmospheric GCM corresponds to which experiment. The scenarios used were taken from Leggett et al. (1992) and the additional scenario E1 was taken from Johns et al. (2011). Scenario A1B and A2 are medium-high emission scenarios, B1 is a low emission scenario and E1 a scenario that introduces aggressive mitigation and translates into lower greenhouse gas (GHG) emissions than B1. The combination of all scenarios was named ALL.

\subsection{The non-stationary log-normal distribution}

The distribution of the annual maximum discharge $x$ in the lower Mekong can be modelled with a log-normal distribution (Dung, 2011). The probability density function is given as (Hosking and Wallis, 1997)

$g(x)=\frac{\exp \left(k X-\frac{X^{2}}{2}\right)}{\alpha \sqrt{2 \pi}}$

and

$X=\left\{\begin{array}{ll}-k^{-1} \log \{1-k(x-\xi) / \alpha\} & \text { if } k \neq 0 \\ (x-\xi) / \alpha & \text { if } k=0\end{array}\right.$,

where $\xi$ is the location parameter, $\alpha$ scale parameter and $k$ is the shape parameter.

While the usual limitations in sample size of annual maximum flood are overcome by fitting a frequency distribution to the data, there is additional uncertainty coming from the fact that floods are phenomena subject to natural variability. Even without considering human-induced climate change, floodrich and flood-poor periods are expected. In the stationary flood frequency framework, the uncertainty related to collecting a sample in a certain time period and not any other is called sampling uncertainty. For a time series of size $N$, the sampling uncertainty can be calculated by drawing a large number $m$ of random samples of size $N$ from the original time series with replacement. By computing the statistic of interest for each of the $m$ samples, a distribution of this statistic can be created, and the uncertainty bounds determined.

Contrary to the standard stationary approach, a nonstationary flood frequency approach was used in this study. The scale parameter of the probability density function was modelled as a function of the non-stationary variance of the monsoon. That is a generalization of the particular case of the usual stationary density function, meaning that the stationary model $\mathcal{M}_{0}$ is nested in the non-stationary model $\mathcal{M}_{1}$ (Coles, 2001; El Adlouni et al., 2007). The scale parameter $\alpha$ was parameterised as a linear function of the non-stationary standard deviation of an atmospheric circulation index $\sigma_{*}(t)$ :

$\alpha(t)=\alpha_{0}+\alpha_{1} \sigma_{*}(t)$.

To estimate the parameters in Eq. (1), the negative loglikelihood $l$ was optimised with the shuffled complex evolution method (Duan et al., 1992). The negative log-likelihood 
Table 1. Names and number of runs of each experiment with a general circulation model. Models that were not rejected by the statistical test explained in Sect. 2.1 are marked with an asterisk.

\begin{tabular}{lcccccl}
\hline & \multicolumn{9}{l}{ \#runs per scenario } & & & Reference \\
& 20C & A1B & B1 & A2 & E1 & \\
\hline BCM2* & 1 & 1 & 1 & 1 & 0 & Otterået al. (2009) \\
CNCM33 & 2 & 1 & 0 & 0 & 0 & Johns et al. (2011) \\
CNCM3 & 5 & 0 & 0 & 0 & 0 & Salas-Mélia et al. (2005) \\
DMICM3 & 2 & 0 & 0 & 0 & 2 & Johns et al. (2011) \\
DMIEH5C & 3 & 3 & 0 & 0 & 0 & Roeckner and Bäuml (2003) \\
DMIEH5* & 1 & 1 & 0 & 0 & 0 & Roeckner and Bäuml (2003) \\
EGMAM2 & 3 & 1 & 0 & 0 & 2 & Huebener et al. (2007) \\
FUBEMA & 3 & 3 & 3 & 3 & 0 & Huebener et al. (2007) \\
HADCM3C $*$ & 1 & 2 & 0 & 0 & 1 & Johns et al. (2003) \\
HADGEM2* & 1 & 3 & 0 & 0 & 2 & Collins et al. (2008) \\
HADGEM $*$ & 6 & 1 & 0 & 1 & 0 & Ringer and Martin (2006) \\
IPCM4V2 & 7 & 3 & 0 & 0 & 3 & Marti et al. (2006) \\
INGVCE* & 1 & 1 & 0 & 0 & 1 & Gualdi et al. (2003) \\
INGVSX $*$ & 1 & 1 & 0 & 1 & 0 & Gualdi et al. (2003) \\
MPEH5C & 3 & 3 & 0 & 0 & 3 & Roeckner and Bäuml (2003) \\
\hline
\end{tabular}

takes the following form:

$l(k, \alpha(t), \xi)=-\sum_{t=1}^{N} \log [g(x(t), k, \alpha(t), \xi)]$

where $N$ is the length of the time series.

The stationary model $\mathcal{M}_{0}$ can be tested against the more general formulation of the non-stationary model $\mathcal{M}_{1}$. The deviance statistic is therefore computed as

$D=2\left(l_{0}-l_{1}\right)$

This quantity is known to be $\chi_{u}^{2}$ distributed (Coles, 2001); $u$ is the additional number of parameters in the non-stationary model.

\subsection{Estimating the time series of the monsoon variance}

Delgado et al. (2012a) showed that the variance of the WNP monsoon and annual maximum discharge in Kratie are in phase and their correlation coefficient is statistically significant for periods below 10 years. This means that the WNP monsoon modulated the annual flood variance for periods lower than 10 years (Grinsted et al., 2004). The variance of the WNP monsoon was therefore extracted by integrating the monsoon wavelet spectrum for periods lower than 10 years.

To obtain a time series of variance, which is necessary as an input to the non-stationary statistical model, the wavelet coefficients are integrated, as given in Torrence and Compo (1998). The result is a time series whose values are an estimate of the contribution of each year to the overall variance. In practice, the variance $\sigma_{*}^{2}(t)$ is given by the following sum- mation:

$\sigma_{*}^{2}(t)=\frac{\delta t \delta j}{C_{\delta}} \sum_{j=j_{1}}^{j_{2}} \frac{\left|W_{n}\left(s_{j}\right)\right|^{2}}{s_{j}}$.

$\delta t$ is the time step of the computation, whereas $\delta j$ is the resolution on the scale domain. In the same sense, $j_{1}$ and $j_{2}$ give the lower and upper limit of the scale function $s_{j}$, which can be translated into a frequency or period in the Fourier sense. $C_{\delta}$ is a constant that depends on the kind of wavelet utilised. $W_{n}$ is the result of the wavelet transform, which can be seen as the convolution of a wavelet over the time series.

The scale-averaged wavelet power is a time series of the averaged variance in a certain frequency band. Note that the same could have been done by computing variance on a moving window. However, the use of the wavelet is not only a moving window, but also filters undesired frequencies, like the low frequencies that account for interdecadal oscillations in the data, and smooths the output.

The time series has to be padded with zeros to the nexthigher power of two before processing the wavelet transform. The Fourier transform assumes that the data is cyclic, so errors would occur without zero-padding. This means that close enough to the edges of the time-series, the wavelet spectrum will be underestimated. To avoid this, the time series was extended with values randomly sampled from the time series instead of zeros. This was done $m$ times in a Monte Carlo approach and each time the wavelet transform was processed. In the end, the results were cropped to the original size and the $m$ wavelet transforms averaged. 


\subsection{A test of equality of variances}

From the GCMs mentioned in Table 1, only some were used in the analysis. A test was performed to reject models whose WNP monsoon variance for the $20 \mathrm{C}$ scenario was significantly different to the reanalysis data. For that, a nonparametric method described in Cahoy (2010) was used, which tests the equality of variances.

The time series of the WNP monsoon intensity were pooled according to the experiment they were derived from, so that for each pool there was a set of time series that belonged to the same experiment. In this test the variance was computed in a stationary sense, that is one value was obtained for each time series and only these values were compared. The time series were previously filtered in order to test only the subdecadal variance. The null hypothesis of the test is that the time series obtained from the reanalysis data have the same variance as the time series in the pool. This would mean that the output of a certain experiment would be good enough for simulating the variance computed from the reanalysis data. By rejecting the null hypothesis, the experiment corresponding to the pool being tested was excluded from the analysis. The significance level used was $5 \%$. By comparing sets of time series with the reanalysis, it was possible to exclude whole experiments instead of individual time series. The natural variability given by different runs within the same experiment was therefore preserved.

\section{Results and discussion}

\subsection{The variance of the monsoon intensity}

The WNP monsoon intensity and its variance were computed from the GCM outputs described in Sect. 2.1. First, the results from the 20th century forcing were analysed. The scatter plot in Fig. 2 shows the mean and variance of the JJAS WNP monsoon intensity for different runs and experiments in the period 1948-1999.

A first observation is that the results are clustered based on atmospheric circulation model and institution, such as the models DMIEH5C and MPEH5C. This is no surprise, since they correspond to the combinations of the same land surface scheme, oceanic circulation model and atmospheric circulation model run by different institutions. DMIEH5 and DMIEH5C, although run in the same institution, present a very different monsoon variance, presumably because they use different versions of the ECHAM5 atmospheric GCM.

The monsoon variance derived from the different GCMs is separated in two clusters. The majority of model realisations is distributed around the reanalysis value. The other cluster, composed of the above-mentioned DMIEH5C and MPEH5C experiments, strongly overestimates monsoon variance. This is mainly due to the results from one particular combination of land surface scheme, ocean circulation and atmospheric
Table 2. Model parameters and estimated $\mathrm{HQ}_{100}$ of the statistical test that rejected the stationary model $\mathcal{M}_{0}$. For $\mathcal{M}_{1}$, the range of $\mathrm{HQ}_{100}$ values represents the variation between 1948 and 2004.

\begin{tabular}{ccccc}
\hline \multicolumn{5}{c}{ Stationary model $\mathcal{M}_{0}$} \\
\hline$k$ & $\alpha_{0}$ & $\alpha_{1}$ & $\xi$ & $\mathrm{HQ}_{100}\left[\mathrm{~m}^{3} \mathrm{~s}^{-1}\right]$ \\
0.0166 & 1.0133 & - & 0.0074 & $64.5 e 3$ \\
\multicolumn{5}{c}{ Non-stationary model $\mathcal{M}_{1}$} \\
\hline$k$ & $\alpha_{0}$ & $\alpha_{1}$ & $\xi$ & $\mathrm{HQ}_{100}\left[\mathrm{~m}^{3} \mathrm{~s}^{-1}\right]$ \\
0.0333 & -0.1257 & 1.3292 & -0.1911 & $\{61.2 e 3,72.2 e 3\}$ \\
\hline \multicolumn{5}{c}{}
\end{tabular}

circulation models. Contrary to the variance, the mean of the monsoon index is less well simulated by most of the model realisations, showing a strong bias compared to reanalysis data.

To overcome the deficient simulation of monsoon variance by some models, a statistical test of heterogeneity (Sect. 2.4) was performed to exclude certain experiments based on their representation of the monsoon variance. The results are given in Table 1. Out of the 15 different model configurations used, 8 were not rejected by the statistical test. For the remaining, the test states with a $5 \%$ significance level that the monsoon intensity from the experiments and from the reanalysis do not have the same variance and were therefore discarded in the remaining investigation. After the removal of the rejected GCMs, the distribution of results is not bimodal anymore and takes the shape of a regular skewed histogram, resembling a skewed distribution of the exponential family.

\subsection{Validation of the flood hazard estimation}

The flood frequency model introduced by Eq. (1) was tested with discharge data from Kratie and Stung Treng for the period 1948-2004. The hydrographs at these stations define the intensity, duration and dynamics of the flood season in the Mekong Delta. In the flood frequency model, the scale parameter is conditioned on the variance of the nonstationary monsoon intensity. During the last decades of the 20th century, annual maximum discharge variance suffered an enhancement that made the occurrence of both exceptionally high and exceptionally low flood events more probable. A similar enhancement was found in the variance of the WNP monsoon index.

In order to prove that the non-stationary extreme value distribution is appropriate, both stationary and non-stationary flood frequency models were statistically tested. Herein, the stationary model $\mathcal{M}_{0}$ is a particular case of the nonstationary model $\mathcal{M}_{1}$, namely for $\alpha_{1}=0$ (cf. Eqs. 1 and 3). Therefore, it is possible to test the null hypothesis of $\mathcal{M}_{0}$ fitting the data better than $\mathcal{M}_{1}$, by evaluating a deviance statistic based on the log-likelihood of the parameter fit. The 


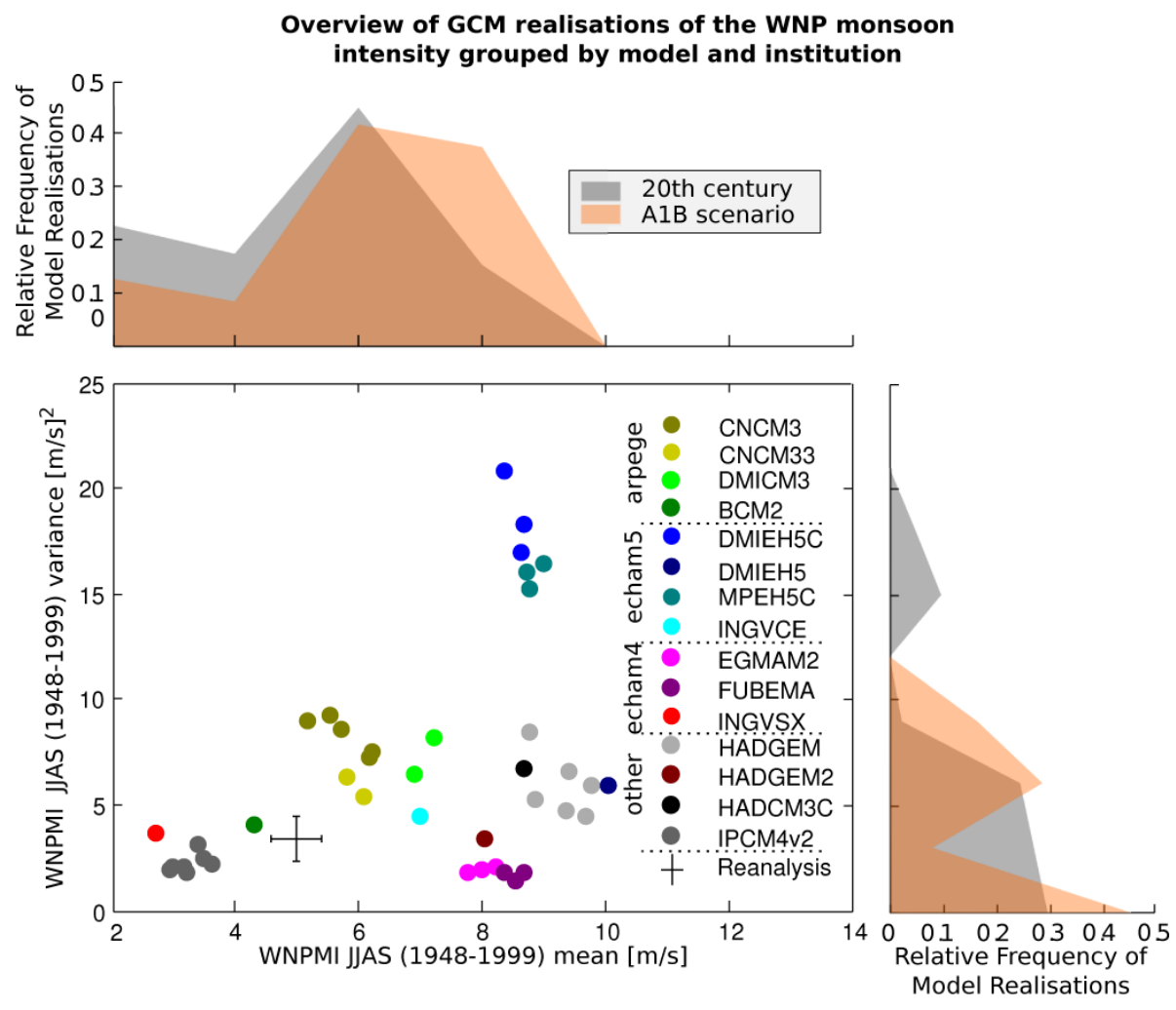

Figure 2. Realisations of WNP monsoon index mean and variance from single runs of the GCM ensemble for the period of 1948 to 1999. The results from the CC scenario A1B are also shown. The WNP monsoon index mean and variance as calculated from reanalysis data are given with $90 \%$ uncertainty bounds.

parameters for both models are shown in Table 2. Model $\mathcal{M}_{1}$ was found to be a significant improvement to the stationary model $\mathcal{M}_{0}$.

A probabilistic approach cannot be validated based on measures of goodness of fit that are normally used in deterministic models. A flood frequency model is fundamentally different from a deterministic model in regard to its validation and its measures of goodness of fit. The frequency of a 100-year event, which is a variable of interest for flood hazard assessment, is by definition very low, meaning that we would need a time series with a length of a higher order of magnitude in order to be able to formally validate the results. Hence, a new model is always compared to a simpler accepted model, and its improvements are assessed by testing their significance regarding the previous version of the model, usually in the same sample used for the optimisation (in this case the previous version was a stationary flood frequency model).

Optimising the parameters of the distribution could be considered a "calibration", whereas the subsequent statistical test could be called "validation". An additional effort was made to prove the robustness of the non-stationary approach based on the variance of the monsoon: several calibration subsets were randomly generated and the model skill was tested when applied to these samples. Another approach con- sisted of evaluating the fitted parameters obtained in these random "calibration" subsets, when applied to their "validation" subsets, which were assumed to be the whole length of the time series. In the first approach, about $97 \%$ of the parameter sets were found significant. In the second approach, the majority of the parameters sets could be validated.

The temporal development of the 100-year return period flood $\mathrm{HQ}_{100}$ estimated by the non-stationary model $\mathcal{M}_{1}$ is presented in Fig. 3a for the 20th century. This estimate (black dashed line) is based on the reanalysis monsoon variance. It lies within the $90 \%$ sampling uncertainty interval of the stationary model $\mathcal{M}_{0}\left(\{61.8 e 3,71.1 e 3\} \mathrm{m}^{3} \mathrm{~s}^{-1}\right)$. Hence, the sampling uncertainty bounds of the stationary approach coincide approximately with the maximum and minimum of the estimates of the non-stationary model. Sampling uncertainty is internalised by $\mathcal{M}_{1}$ when the interannual variance of the monsoon is parameterised.

When forced by GCM outputs, rather than by reanalysis data, the range of results of $\mathcal{M}_{1}$ is much wider (Fig. 3a). Thus GCM uncertainty is greater than what can be expected from natural variability. It is worth mentioning that the uncertainty range given by $\mathcal{M}_{1}$ forced by GCM outputs would have been even greater if some models had not been statistically rejected, as seen in the dotted black line in Fig. 3. The 


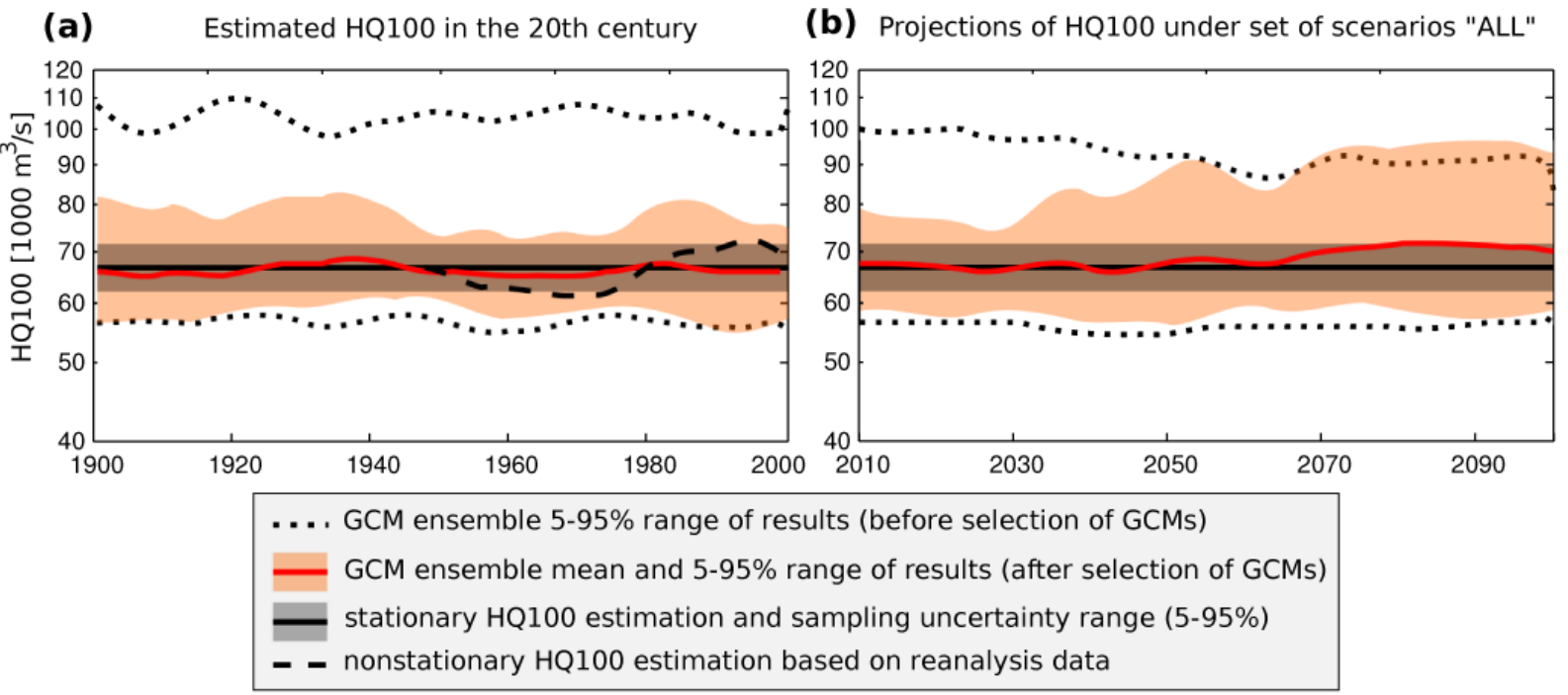

Figure 3. $\mathrm{HQ}_{100}$ in Kratie obtained by fitting a statistical model to the results of the ensemble of GCMs. The ensemble mean is drawn in red with its 5th and 95th percentile. The black dashed line is the application of the non-stationary model to the monsoon index based on the reanalysis data. In addition, $\mathrm{HQ}_{100}$ estimated by the stationary model $\mathcal{M}_{0}$ on the basis of the observed flood peaks, including the $90 \%$ sampling uncertainty, is shown (black solid line). (a) shows results based on measured and reanalysis data, together with GCM results under the baseline scenario 20C; (b) shows GCM results for the set of all scenarios considered ALL.

excluded models would have largely overestimated $\mathrm{HQ}_{100}$ at values that are way beyond the flood of record.

The ensemble mean of the GCM estimations of flood hazard for the 20th century is the red line given in Fig. 3. The ensemble mean is very close to the stationary estimation and always within the sampling uncertainty of the stationary flood frequency distribution. The edges of the time series should be interpreted with care, though, since a correction based on a synthetic prolongation of the data was performed to avoid boundary effects (see Sect.2.3).

\subsection{The 100-year flood in Kratie under CC}

The change projected by the set of scenarios ALL is insignificant for most of the 21 st century, because it stays within the sampling uncertainty of the stationary model based on the observation data for the period 1924-2009. Emission scenarios play a role in the $\mathrm{CC}$ projections, though. Figure 4 shows the box plot of the 100-year flood in 2050 for A1B, E1 and ALL scenarios. A difference between the three emission scenarios is observable. The ensemble mean is higher for scenario A1B than for E1 and ALL. The 95\% uncertainty range changes from $54.7 e 3,96.4 e 3 \mathrm{~m}^{3} \mathrm{~s}^{-1}$ under A1B to $56.7 e 3,80.0 e 3 \mathrm{~m}^{3} \mathrm{~s}^{-1}$ under E1.

Another important feature is the temporal variation of the ensemble mean and uncertainty. The estimations of the 100year flood are shown in Fig. 3b. The red line represents the ensemble mean of GCM runs for the ALL set of scenarios considered in Table 1. The ensemble mean has the tendency to increase with time but only leaves the uncertainty range estimated for $\mathrm{HQ}_{100}$ for the 20th century shortly in the end
GCM derived estimations of HQ100

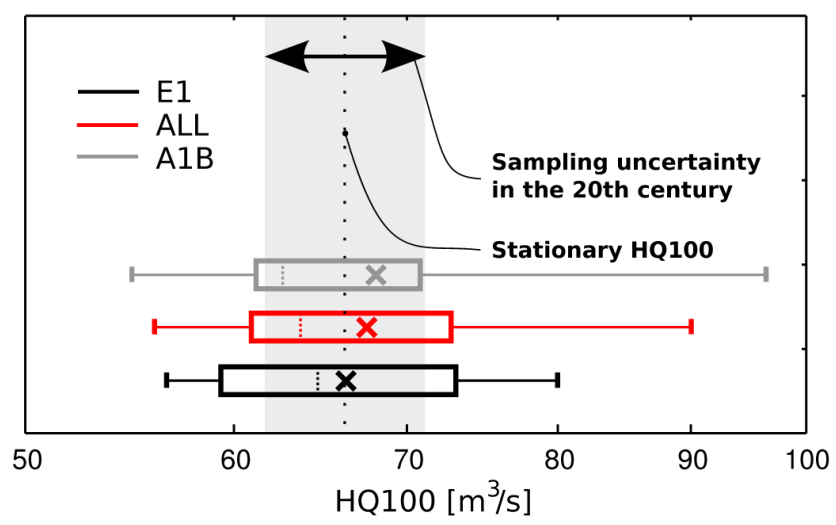

Figure 4. The results of the Monte Carlo simulation of $\mathrm{HQ}_{100}$ for 2050 based on two different scenarios (A1B and E1) and the combination of all emission scenarios ALL for the 21st century. The 5th, 25th, 50th, 75th and 95th percentiles of the GCM ensemble are given by the boxplots. The ensemble mean is marked with a cross. The $90 \%$ sampling uncertainty of the 20th century 100 -year flood is also shown in grey shading.

of the modelled domain. Also, the spread of the ensemble increases with time, mainly due to a change in the upper bound.

In general, an increase in the ensemble mean is observed in 2050 (Fig. 4), when the CC projections are compared with the stationary model for the 20th century, although the ensemble median decreases. Under scenario A1B, the empirical ensemble mean shows the greatest value in the projections of 
$\mathrm{HQ}_{100}$ in 2050. The increase in $\mathrm{HQ}_{100}$ under the scenarios considered is not statistically significant, as it lies within the natural uncertainty estimated for the 20th century $\mathrm{HQ}_{100}$.

Due to the non-stationary characteristics of the model, it is difficult to compare the presented results with the few studies in the literature that focused on changes in the variance of floods in the Mekong River. Many investigations have different reference periods: for example, Arnell (2003) compares the coefficient of variation of annual runoff around 2050 in the Mekong Basin with measurements in 1961-1990. Increases and decreases in this parameter are dependent on the scenario used. Other investigations use control runs, where GHG concentrations are kept constant, instead of 20th century baseline scenarios, where GHG concentrations follow the historical trends and therefore cannot be compared with the present study.

Sperna Weiland et al. (2011) found an insignificant increase in variance of mean annual discharge between A1B scenario between 2081 and 2100 and a baseline scenario for the 20th century between 1971 and 1990. The study used an ensemble of GCMs and also projected a significant increase in average annual maximum discharge of about $50 \%$ at Mukdahan (approximately halfway between the border with China and the river mouth).

The only study that focuses explicitly on the variance of floods is Arora (2001). An increase of 5\% in the standard deviation of annual floods is predicted, although the 5 and 50 -year return period flood decreases by 28 and $15 \%$, respectively. The results are a comparison between control scenario and CC scenarios from 2070 to 2100 and are statistically significant, although an estimation of GCM or hydrological model uncertainty is not provided. The study presents the result of only one GCM, so the decrease in flood variance could very well be contained within the GCM ensemble uncertainty range presented in Fig. 3b, although the $15 \%$ decrease in 50year return period floods is a remarkable figure.

Hoanh et al. (2010) and Eastham et al. (2008), among others, point to an increase in flood hazard. Lauri et al. (2012) interestingly conclude that changes introduced by reservoir operation of projected dams are likely to have stronger impacts on the floods of the Mekong than CC. The CC scenarios, however, increased the uncertainty of estimated hydropower impact. This is in line with the present study, where it was found that GCMs cannot predict whether there is a significant increase or decrease in flood hazard, due to high uncertainty. Although these results do not provide a crisp statement about flood hazard under $\mathrm{CC}$, they are very helpful in providing a space of possible future realisations of flood hazard change.

The WNP monsoon index used is based on zonal wind velocity at $850 \mathrm{hPa}$ geopotential height. An attempt is therefore made to avoid the use of often badly represented tropical and monsoonal precipitation by GCMs (Randall et al., 2007). Wang et al. (2004) discussed the particular case of the East Asian monsoon region and found that the poor simulation of rainfall in the region is a "striking characteristic of all the models" tested, while the WNP monsoon index could be realistically represented.

It is important to say that the estimation of flood hazard presented has only one explanatory variable. Based on the forcing of the monsoon, a relationship between the interannual variance of the WNP monsoon and the annual maximum discharge in Kratie is found that explains the variation of the scale parameter. It is however acknowledged that other factors play a role in flood generation, such as land use change (Bernard and Koninck, 1997), land management (Haddeland et al., 2006), dam building (Lauri et al., 2012) and local meteorological conditions (Hsu et al., 2008) that may not be related to the larger monsoon circulation. There is however a point in assessing the impacts of a change in the monsoon regime, since it constitutes the dominant factor for floods in the lower Mekong Basin.

\section{Conclusions}

The novel approach introduced in this paper is an alternative to the use of the typical model chain to estimate CCdriven changes in flood hazard. The method can be applied to regions where one main forcing mechanism is well quantified in the relevant timescale. The monsoon is such a forcing mechanism with a strong annual periodicity matching that of the annual flood season. In other regions where more than one main atmospheric circulation pattern contributes to flood generation this approach would be more difficult. However, other atmospheric phenomena of strong interannual variability exist that can serve as driver for conditioning statistical model parameters (e.g. Kwon et al., 2008).

We showed that the relationship between monsoon variance and flood variance has implications for flood risk assessment. By creating a non-stationary statistical model that is forced by monsoon variance, we were able to provide a range of projections of flood hazard under CC. The subdecadal variance of the WNP monsoon index previously proved to be a statistically significant covariate for the scale parameter of a flood frequency model (Delgado et al., 2012b). We used the zonal wind velocity as described by Wang et al. (2001) to compute a WNP monsoon index based on GCM ensemble runs under several CC scenarios.

The projection of the 100-year return period flood under $\mathrm{CC}$ was presented as a range of results based on the GCM ensemble, rather than as only one value. The ensemble mean for 2010-2090 is slightly greater than the stationary estimation of the 100-year flood for the 20th century, and regarding the end of the modelled domain, the ensemble mean leaves the range of uncertainty calculated for the stationary $\mathrm{HQ}_{100}$ in the 20th century. The 5 and $95 \%$ average uncertainty bounds of the non-stationary $\mathrm{HQ}_{100}$, when forced by the GCMs, are $57.5 e 3$ and $86.4 e 3 \mathrm{~m}^{3} \mathrm{~s}^{-1}$, respectively. This is a greater interval than the uncertainty bounds of $61.2 e 3$ to $72.2 e 3 \mathrm{~m}^{3} \mathrm{~s}^{-1}$ estimated with the stationary model for the 20th century data, 
but still within range of what are believed to be realistic discharge values for the Mekong River (the instantaneous discharge of the 1978 event has been estimated from $72 e 3$ to $78 e 3 \mathrm{~m}^{3} \mathrm{~s}^{-1}$, MRC, 2005).

This approach is a simple way of creating a space of possible future realisations of flood hazard change. To date it is not possible to make a statement regarding the impact of climate change on the flood regime of the Mekong River with a reliable statistical significance. The GCMs produce a range of results that includes both negative and positive change and the ensemble mean is not clearly different from the reference period. This is due both to GCM uncertainty and to the non-stationary nature of our approach (averaging the results across several decades would have likely reduced the uncertainty range). The results of this study should be taken as a range of CC scenarios in the Mekong River. Approaches that use only one or a very small number of climate change model chains without provision of an uncertainty range should be avoided, as this can easily mislead flood risk management.

Our alternative approach, based on a shortened model chain, has three advantages: (1) it bypasses precipitation which is badly represented by climate models in our study area. (2) Its simplicity allows for deriving large ensembles of flood projections almost immediately from the output from global climate models - an important characteristic in comparison to the efforts needed to implement, calibrate/validate and run the typical climate change model chains. (3) It reduces complexity: the huge amount of parameters, processes, interactions between processes and interactions in space and time of typical model chains impedes the understanding of how changes in certain processes or parameters are transferred to changes in flood hazard. The direct linkage between changes in atmospheric circulation systems and flood hazard used here is not plagued by such complexity. Overall, we conclude that the fundamental idea underlying this approach, namely to search for and to focus on dominant driver-impact linkages, is a worthwhile avenue, not substituting but complementing the usual climate model chain approach.

Acknowledgements. J. Delgado acknowledges the portuguese Foundation for Science and Technology, as well as the German Federal Ministry of Education and Research.

Edited by: A. Loukas

Reviewed by: Y. Tramblay and four anonymous referees

\section{References}

Allen, M. R. and Ingram, W. J.: Constraints on future changes in climate and the hydrologic cycle, Nature, 419, 224-232, 2002.

Arnell, N. W.: Effects of IPCC SRES* emissions scenarios on river runoff: a global perspective, Hydrol. Earth Syst. Sci., 7, 619-641, doi:10.5194/hess-7-619-2003, 2003.
Arora, V. K.: Effects of simulated climate change on the hydrology of major river basins, J. Geophys. Res., 106, 3335-3348, 2001.

Bernard, S. and Koninck, R.: The retreat of the forest in Southeast Asia: a cartographic assessment, Singapore J. Trop. Geo., 17, 114, doi:10.1111/j.1467-9493.1996.tb00080.x, 1997.

Blöschl, G. and Montanari, A.: Climate change impacts - Throwing the dice?, Hydrol. Process., 381, 374-381, doi:10.1002/hyp.7574, 2009.

Bouwer, L. M., Vermaat, J. E., and Aerts, J. C. J. H.: Winter atmospheric circulation and river discharge in northwest Europe, Geophys. Res. Lett., 33, L06403, doi:10.1029/2005GL025548, 2006.

Cahoy, D. O.: A bootstrap test for equality of variances, Computat. Stat. Data An., 54, 2306-2316, doi:10.1016/j.csda.2010.04.012, 2010.

Cayan, D. R.: Interannual climate variability and snowpack in the western United States, J. Climate, 9, 928-948, 1996.

Cayan, D. R., K. Redmond, and Riddle, L.: ENSO and Hydrologic Extremes in the Western United States*, J. Climate, 2881-2893, 1999.

Coles, S.: An introduction to statistical modeling of extreme values, Springer, 2001.

Collins, W. J., Bellouin, N., Doutriaux-Boucher, M., Gedney, N., Hinton, T., Jones, C., Liddicoat, S., Martin, G., O'Connor, F., Rae, J., Senior, C., Totterdell, I., and Woodward, S.: Hadley Centre technical note 74, Tech. Rep. November, Met Office Hadley Centre, Exeter, UK, 2008.

Delgado, J. M., Merz, B., and Apel, H.: A climate-flood link for the lower Mekong River, Hydrol. Earth Syst. Sci., 16, 1533-1541, doi:10.5194/hess-16-1533-2012, 2012a.

Delgado, J. M., Merz, B., and Apel, H.: Monsoon variability and the Mekong flood regime, in: The Mekong Delta System - Interdisciplinary Analysis of a River Delta, edited by: Renaud, F. and Künzer, C., Chap. 7, Springer, Berlin, Heidelberg, 2012b

Deser, C., Phillips, A., Bourdette, V., and Teng, H.: Uncertainty in climate change projections: the role of internal variability, Clim. Dynam., 38, 527-546, doi:10.1007/s00382-010-0977-x, 2010.

Douville, H., Salas-Mélia, D., and Tyteca, S.: On the tropical origin of uncertainties in the global land precipitation response to global warming, Clim. Dynam., 26, 367-385, doi:10.1007/s00382-0050088-2, 2005.

Duan, Q., Sorooshian, S., and Gupta, V.: SAC-SMA, Water Resour., 28, 1015-1031, 1992.

Dung, N. V.: Multi-objective automatic calibration of hydrodynamic models - development of the concept and an application in the Mekong Delta, Ph.D. thesis, University of Stuttgart, 2011.

Eastham, J., Mpelasoka, F., Mainuddin, M., Ticehurst, C., Dyce, P., Hodgson, G., Ali, R., and Kirby, M.: Mekong River Basin Water Resources Assessment: Impacts of Climate Change, Tech. rep., CSIRO: Water for a Healthy Country National Research Flagship, 2008.

El Adlouni, S., Ouarda, T B. M. J., Zhang, X., Roy, R., Bobé, B., Generalized maximum likelihood estimators for the nonstationary generalized extreme value model. Water Resour. Res., 43, W03410, doi:10.1029/2005WR004545, 2007.

Grinsted, A., Moore, J. C., and Jevrejeva, S.: Application of the cross wavelet transform and wavelet coherence to geophysical time series, Nonlin. Processes Geophys., 11, 561-566, doi:10.5194/npg-11-561-2004, 2004. 
Gualdi, S., Navarra, A., Guilyardi, E., and Delecluse, P.: Assessment of the tropical Indo-Pacific climate in the SINTEX CGCM, Ann. Geophys., 46, 1-26, doi:10.4401/ag-3385, 2003

Haddeland, I., Lettenmaier, D. P., and Skaugen, T.: Effects of irrigation on the water and energy balances of the Colorado and Mekong river basins, J. Hydrol., 324, 210-223, 2006.

Hoanh, C. T., Jirayoot, K., Lacombe, G., and Srinetr, V.: Impacts of climate change and development on the Mekong flow regime. First assessment - 2009. MRC Technical Paper No. 29, Tech. Rep. 29, Mekong River Commission, Vientiane, Lao PDR, 2010.

Holmes, J. A., Cook, E. R., and Yang, B.: Climate change over the past 2000 years in Western China, Quaternary Int., 194, 91-107, doi:10.1016/j.quaint.2007.10.013, 2009.

Hosking, J. R. M. and Wallis, J. R.: Regional frequency analysis, 224 pp., Cambridge University Press, Cambridge, 1997.

Hsu, H.-H., Hung, C.-H., Lo, A.-K., Wu, C.-C., and Hung, C.-W.: Influence of tropical cyclones on the estimation of climate variability in the tropical western North Pacific, J. Climate, 21, 29602975, doi:10.1175/2007JCLI1847.1, 2008.

Huebener, H., Cubasch, U., Langematz, U., Spangehl, T., Niehörster, F., Fast, I., and Kunze, M.: Ensemble climate simulations using a fully coupled ocean-troposphere-stratosphere general circulation model, Philos. T. Roy. Soc. A, 365, 2089-101, doi:10.1098/rsta.2007.2078, 2007.

Jain, S. and Lall, U.: Magnitude and timing of annual maximum floods: trends and large-scale climatic associations for the Blacksmith Fork River, Utah, Water Resour. Res., 36, 3641-3651, doi:10.1029/2000WR900183, 2000.

Jain, S. and Lall, U.: Floods in a changing climate: does the past represent the future?, Water Resour. Res., 37, 3193-3205, 2001.

Johns, T. C., Gregory, J. M., Ingram, W. J., and Johnson, C. E.: Anthropogenic climate change for 1860 to 2100 simulated with the HadCM3 model under updated emissions scenarios, Clim. Dynam., 583-612, doi:10.1007/s00382-002-0296-y, 2003.

Johns, T. C., Royer, J.-F., Höschel, I., Huebener, H., Roeckner, E., Manzini, E., May, W., Dufresne, J.-L., Otterå, O. H., Vuuren, D. P., Salas-Mélia, D., Giorgetta, M. A., Denvil, S., Yang, S., Fogli, P. G., Körper, J., Tjiputra, J. F., Stehfest, E., and Hewitt, C. D.: Climate change under aggressive mitigation: the ENSEMBLES multi-model experiment, Clim. Dynam., 37, 1975-2003, doi:10.1007/s00382-011-1005-5, 2011.

Kajikawa, Y. and Wang, B.: Monsoon Monitoring Page, 2012.

Kingston, D. G., Lawler, D., and McGregor, G.: Linkages between atmospheric circulation, climate and streamflow in the northern North Atlantic: research prospects, Prog. Phys. Geog., 30, 143174, doi:10.1191/0309133306pp471ra, 2006.

Kingston, D. G., Thompson, J. R., and Kite, G.: Uncertainty in climate change projections of discharge for the Mekong River Basin, Hydrol. Earth Syst. Sci., 15, 1459-1471, doi:10.5194/hess-15-1459-2011, 2011.

Knox, J. C.: Sensitivity of modern and Holocene floods to climate change, Quaternary Sci. Rev., 19, 439-457, 2000.

Kwon, H.-H., Brown, C., and Lall, U.: Climate informed flood frequency analysis and prediction in Montana using hierarchical Bayesian modeling, Geophys. Res. Lett., 35, 1-6, doi:10.1029/2007GL032220, 2008.

Lambert, S. J. and Boer, G. J.: CMIP1 evaluation and intercomparison of coupled climate models, Clim. Dynam., 17, 83-106, doi:10.1007/PL00013736, 2001.
Lauri, H., de Moel, H., Ward, P. J., Räsänen, T. A., Keskinen, M., and Kummu, M.: Future changes in Mekong River hydrology: impact of climate change and reservoir operation on discharge, Hydrol. Earth Syst. Sci., 16, 4603-4619, doi:10.5194/hess-164603-2012, 2012.

Leggett, J., Pepper, W. J., and Swart, R. J.: Emissions scenarios for the IPCC: an update, in: Climate change 1992, edited by: Houghton, J. T., Callander, B. A., and Varney, S. K., the supplementary report to the IPCC scientific assessment, Cambridge Univ Press, Cambridge, 75-95, 1992.

López, J. and Francés, F.: Non-stationary flood frequency analysis in continental Spanish rivers, using climate and reservoir indices as external covariates, Hydrol. Earth Syst. Sci., 17, 3189-3203, doi:10.5194/hess-17-3189-2013, 2013.

Mantua, N. J., Hare, S. R., Zhang, Y., Wallace, J. M., and Francis, R. C.: A Pacific interdecadal climate oscillation with impacts on salmon production, B. Am. Meteorol. Soc., 78, 1069-1079, doi:10.1175/1520-0477(1997)078<1069:APICOW>2.0.CO;2, 1997.

Marti, O., Braconnot, P., Bellier, J., Benshila, R., Bony, S., Brockmann, P., Cadule, P., Caubel, A., Denvil, S., Fairhead, L., Fichefet, T., Friedlingstein, P., Gosse, H., Hourdin, F., Krinner, G., Madec, G., Musat, I., Noblet, N. D., Polcher, J., and Talandier, C.: The new IPSL climate system model: IPSL-CM4, Tech. rep., Institut Pierre Simon Laplace, Paris, 2006.

Milly, P. C. D., Wetherald, R. T., Dunne, K. A., and Delworth, T. L.: Increasing risk of great floods in a changing climate, Nature, 415 , 514-517, 2002.

Milly, P. C. D., Dunne, K. A., and Vecchia, A. V.: Global pattern of trends in streamflow and water availability in a changing climate, Nature, 438, 347-350, 2005.

MRC: Overview of the Hydrology of the Mekong Basin, Tech. rep., Mekong River Commission, Vientiane, 2005.

Otterå, O. H., M. Bentsen, and ethke, I. B: Simulated pre-industrial climate in Bergen Climate Model (version 2): model description and large-scale circulation features, Geosci. Model, 2, 197-212, 2009.

Pizarro, G. and Upmanu Lall: El Niño-induced flooding in the US West: what can we expect?, EOS Transactions, 83, 349-352, doi:10.1029/2002EO000255, 2002.

Randall, D. A., Wood, R. A., S. Bony, R. Colman, T. Fichefet, J. Fyfe, V. Kattsov, A. Pitman, J. Shukla, J. Srinivasan, Stouffer, R. J., A. Sumi, and Taylor, K. E.: Climate models and their evaluation, in: Climate Change 2007: The Physical Science Basis, Contribution of Working Group I to the Fourth Assessment Report of the Intergovernmental Panel on Climate Change, edited by: Solomon, S., Qin, D., Manning, M., Chen, Z., Marquis, M., Averyt, K. B., Tignor, M., and Miller, H. L., Chap. 8, Cambridge University Press, Cambridge, UK, New York, USA, 2007.

Ringer, M. and Martin, G.: Physical properties of the atmosphere in the new Hadley Centre Global Environmental Model (HadGEM1) - Part 2: Aspects of variability and regional climate, J. Climate, 1302-1326, 2006.

Roeckner, E. and Bäuml, G.: The Atmospheric General Circulation Model ECHAM5, Tech. Rep. 349, Max Planck Institute for Meteorology, Hamburg, 2003. 
Salas-Mélia, D., Chauvin, F., Déqué, M., Douville, H., Gueremy, J. F., Marquet, P., Planton, S., Royer, J. F., and Tyteca, S.: Description and validation of the CNRM-CM3 global coupled model, Clim. Dynam., 103, 1-36, 2005.

Sankarasubramanian, A. and Lall, U.: Flood quantiles in a changing climate: seasonal forecasts and causal relations, Water Resour. Res., 39, 5, 2003.

Sperna Weiland, F. C., van Beek, L. P. H., Kwadijk, J. C. J., and Bierkens, M. F. P.: Global patterns of change in discharge regimes for 2100, Hydrol. Earth Syst. Sci., 16, 1047-1062, doi:10.5194/hess-16-1047-2012, 2012.

Teutschbein, C. and Seibert, J.: Regional climate models for hydrological impact studies at the catchment scale: a review of recent modeling strategies, Geogr. Compass, 4, 834-860, 2010.

Torrence, C. and Compo, G. P.: A practical guide to wavelet analysis, B. Am. Meteorol. Soc., 79, 61-78, 1998.

Tramblay, Y., Neppel, L., Carreau, J. and Najib, K., Nonstationary frequency analysis of heavy rainfall events in southern France, Hydrol. Sci. J., 58, 280-294, doi:10.1080/02626667.2012.754988, 2013

Turner, A. and Annamalai, H.: Climate change and the South Asian summer monsoon, Nat. Clim. Change, 2, 587-595, doi:10.1038/nclimate1495, 2012.

Villarini, G., Serinaldi, F., Smith, J. A., and Krajewski, W. F.: On the stationarity of annual flood peaks in the continental United States during the 20th century, Water Resour. Res., 45, W08417, doi:10.1029/2008WR007645, 2009.
Wang, B., Wu, R., and Lau, K.-M.: Interannual variability of the Asian summer monsoon: contrasts between the Indian and the Western North Pacific-East Asian Monsoons, J. Climate, 14, 4073-4090, 2001.

Wang, B., Kang, I.-S., and Lee, J.-Y.: Ensemble simulations of Asian-Australian Monsoon variability by 11 AGCMs, J. Climate, 17, 803-818, doi:10.1175/15200442(2004)017<0803:ESOAMV>2.0.CO;2, 2004.

Ward, P. J., Eisner, S., Flörke, M., Dettinger, M. D. and Kummu, M.: Annual flood sensitivities to El Niño Southern Oscillation at the global scale, Hydrol. Earth Syst. Sci., 18, 47-66, doi:10.5194/hess-18-47-2014, 2014

Waylen, P. and Caviedes, C.: El Niño and annual floods on the north Peruvian littoral, J. Hydrol., 89, 141-156, 1986.

Whitcher, B., Byers, S. D., Guttorp, P., and Percival, D. B.: Testing for homogeneity of variance in time series: Long memory, wavelets, and the Nile River, Water Resour. Res., 38, 1054-1069, 2002.

Zhang, Q., Xu, C.-Y., Jiang, T., and Wu, Y.: Possible influence of ENSO on annual maximum streamflow of the Yangtze River, China, J. Hydrol., 333, 265-274, 2007. 